\title{
O TEATRO EM MATO GROSSO (1877-1928)
}

\author{
Marcela Ariete dos Santos ${ }^{1}$
}

Resumo: Este artigo descreve como esteve organizado o teatro em Mato Grosso no período de 1877 a 1928. Em 1877 surgiu a "Amor à Arte”, uma instituição teatral que se destacou na óptica da imprensa. Em meados de 1928, os empresários mato-grossenses vislumbram o teatro como algo promissor para o mercado de entretenimento. Em termos metodológicos, a pesquisa se caracterizou por um estudo histórico, utilizando-se de jornais publicados do estado de Mato Grosso, digitalizados e disponíveis na hemeroteca digital, no primeiro semestre de 2016. Identifica-se que os espaços físicos do teatro em Mato Grosso eram todos particulares e tinham estruturas incipientes; as instituições/agremiações teatrais buscavam promover distrações por meio de espetáculos teatrais ou outros divertimentos; essas instituições não sobreviviam por muito tempo, principalmente por falta de recursos financeiros. Além dessas instituições amadoras, apareceram também as companhias itinerantes que se instalavam em Mato Grosso por tempo determinado. Constata-se ainda que as comédias, os vaudevilles, as operetas, as zarzuelas e o teatro de revista foram os gêneros apresentados em Mato Grosso e os telespectadores, eram na maioria das vezes pessoas mais elitizadas.

Palavras-chaves: Teatro; Mato Grosso, História; Diversão; Entretenimento.

\section{EL TEATRO EN MATO GROSSO (1877-1928)}

Resumen: Este artículo describe como fue organizada el teatro en Mato Grosso en el período de 1877 a 1928. En 1877 llegó a "Amor à Arte", Una institución teatral que se destacó desde la perspectiva de la prensa. En medio de 1928, los empresarios mato-grossenses vislumbró el teatro como algo prometedor para el mercado del entretenimiento. En términos metodológicos, la investigación se caracterizó para un estudio histórico, usando periódicos publicados en el estado de Mato Grosso, escaneado y disponible en la hemeroteca digital, en la primera mitad de 2016. Se identifica que los espacios físicos del teatro en Mato Grosso eran todos privados y tenían estructuras incipientes; instituciones / asociaciones teatrales que buscaban promover distracciones a través de espectáculos teatrales u otro entretenimiento; estas instituciones no sobrevivieron por mucho tiempo, principalmente debido a la falta de recursos financieros. Además de estas instituciones amateur, también aparecieron empresas itinerantes que se establecieron en Mato Grosso por un tiempo determinado. También se observa que las comedias, vodevilles, operetas, zarzuelas y teatro de revistas fueron los géneros presentados en Mato Grosso y los espectadores fueron, en la mayoría de los casos, personas más elitistas.

\footnotetext{
${ }^{1}$ Mestra em Estudo do Lazer pela UFMG. Professora substituta do curso de Educação Física da Universidade Estadual de Mato Grosso - UNEMAT. E-mail: marcelaariete@gmail.com. ORCID: https://orcid.org/0000-00032271-6555.
} 
Palabras clave: Teatro; Mato Grosso, Historia; Divertido; Entretenimiento.

\title{
THEATER IN MATO GROSSO (1877-1928)
}

\begin{abstract}
This paper describes how the theater was organized in the Brazilian state of Mato Grosso from 1877 to 1928. In 1877 show up "Amor à Arte", a theatrical company that apparently got prominence from the press perspective at the time. In the middle of 1928, entrepreneurs from Mato Grosso considered the theater as something promising for the entertainment market. In methodological terms, the research was characterized by a historical study, using newspapers published between 1877 and 1928, from Mato Grosso, digitized and available in the digital library Hemeroteca, in the first half of 2016. It was identified that the physical spaces of the theater were all private and had incipient structures; theatrical company/associations provided the society of the state with distractions through theatrical shows or other entertainment; these institutions did not last for long, mainly due to lack of financial resources. Besides amateur institutions, itinerant companies that established themselves there for a specific time also appeared. It is also noted that comedies, vaudevilles, operettas, zarzuelas, and magazine theater were the genres presented in Mato Grosso and the viewers were, in most cases, more elitist people.
\end{abstract}

Keywords: Theather, Mato Grosso, History, Fun, Entertainment.

\section{Introdução}

Este trabalho buscou investigar o teatro em Mato Grosso no período de 1877 a 1928 como um elemento de "diversão", na mesma perspectiva de Melo e Alves Jr. (2012) ao dizerem que a busca pela diversão e atividades prazerosas para além do trabalho sempre foi algo muito importante para os seres humanos. Assim, o principal objetivo foi descrever, sob a óptica da imprensa local, como esta prática esteve organizada.

O recorte temporal começa em 1877, quando em Cuiabá, surgira a “Amor à Arte”, uma instituição teatral que pareceu se destacar na imprensa. O escopo fecha-se então em meados de 1928, momento em que os empresários mato-grossenses pareceram vislumbrar o teatro como algo promissor para o mercado de entretenimento.

Em termos metodológicos, a pesquisa se caracterizou por um estudo histórico, utilizando-se de jornais, publicados de 1877 a 1928 em Mato Grosso, digitalizados e disponíveis gratuitamente na hemeroteca digital ${ }^{2}$. A busca neste portal ocorreu no primeiro semestre de 2016. A palavra-chave "teatro" e termos de mesmo valor semântico como "espaços teatrais" e "peças" foram usadas na recuperação das fontes. Inicialmente, 1200 (um mil e duzentas)

\footnotetext{
${ }^{2}$ A Fundação Biblioteca Nacional oferece aos seus usuários a Hemeroteca Digital Brasileira, portal de periódicos nacionais que proporciona ampla consulta, pela internet, ao seu acervo de periódicos - jornais, revistas, anuários, boletins etc. - e de publicações seriadas. Disponível no site: http://bndigital.bn.br/hemeroteca-digital/
} 
notícias foram levantadas; estes registros passaram por um filtro selecionando apenas as que abordavam o teatro numa perspectiva da diversão. Por fim, foram transcritas e analisadas aproximadamente 400 (quatrocentas) notícias.

Vale destacar que o teatro no Brasil, teve seus primeiros registros a partir do século XVI com a vinda dos padres da Companhia de Jesus após os portugueses terem conquistado o país (SÁ, 2005). Nasceu sob auspícios da religião católica, com sermões dramatizados de José de Anchieta, o qual produziu autos com fundo especialmente religioso, moral, com finalidades catequéticas e pedagógicas (PRADO, 1999). Sua origem está toda no teatro português, que por sua vez, é caudal do teatro espanhol, italiano e francês. Estas características foram recorrentemente confirmadas no cenário teatral mato-grossense (LOTT, 1987).

De início as práticas teatrais pareceram se concentrar mais ao norte do país, tendo como centro Salvador, na Bahia, e posteriormente Rio de Janeiro. No interior o teatro só penetrou em algumas capitanias como Minas Gerais e Mato Grosso, onde a descoberta de ouro ou pedras preciosas gerou riquezas e improvisou as cidades (PRADO, 1999).

Embora as evidências tenham mostrado que o teatro no Brasil existiu desde o primeiro período de sua colonização, Dias (2012) acrescenta que esta prática só começou a apresentar um nível artístico e cultural apreciável a partir do século XIX, após ter se instalado no Rio de Janeiro a Família Real Portuguesa. Sá (2005) complementa que foi a partir desse século que realmente o teatro brasileiro alçou voos mais largos. Construiu-se então o primeiro teatro e os gêneros começaram a se diversificar e adquirir, ainda que em pequenas proporções, características mais nacionalistas. É neste período que este trabalho esteve inserido e pôde constatar que o estado de Mato Grosso também obtivera conquistas e se alinhava ao cenário teatral do país, principalmente no que se referiu às companhias visitantes e às peças por elas apresentadas.

Além disso, em Mato Grosso, o teatro pareceu ser um elemento de influência no desenvolvimento cultural da região. O motivo de tal importância pode estar atrelado à precocidade com que se iniciaram suas atividades teatrais, ainda no século XVIII, junto aos primeiros esforços de sua colonização. As fontes indicam que até mesmo o período colonial teria testemunhado a época áurea do teatro em Mato Grosso. Nessa época, os administradores da Capitania incentivavam a realização de festas populares com apresentações teatrais, como parte da estratégia para consolidar a "dominação" colonial por meio da cultura. Já no fim do século XIX o teatro em Mato Grosso assim como o teatro brasileiro assume um diálogo “civilizador" (LOTT, 1987). 
Além do teatro, outras práticas de diversões em Mato Grosso revelaram-se importantes para seu povo neste período: as cavalhadas, as touradas, as festas do Divino Espírito Santo, dentre outras. Interessante que tanto as práticas teatrais inseridas nas programações quanto o próprio espaço físico do teatro estavam coadunados com estes divertimentos no estado (A GAZETA, 1889a, p. 1; O REPUBLICANO, 1898c, p. 4; A NOTICIA, 1927, p. 4). Além dos espetáculos como atrações noturnas, os espaços teatrais também apareceram sediando reuniões e acertos das comissões organizadoras desses festejos (O REPUBLICANO, 1898b, p. 4).

Até a década de 1920, as manifestações teatrais em Mato Grosso estiveram concentradas nas cidades de Cuiabá e Corumbá, com algumas aparições esporádicas em outras cidades matogrossenses, como Cáceres, Ladário, Três Lagoas, Campo Grande. Cuiabá e Corumbá, neste período, eram as cidades de maior expressão política em Mato Grosso. Embora a capital se sobressaísse por concentrar grande parte da elite local, a atividade portuária conferia à Corumbá uma significativa posição no cenário político regional (FRANCO, 2019).

Deste modo, o trabalho apresenta detalhadamente quais eram os espaços físicos do teatro, as instituições amadoras, as instituições itinerantes atuantes na época, as peças e o público que apreciava esta prática em Mato Grosso. Revela também que o teatro em Mato Grosso, além de entretenimento, tivera importância entre os ideais civilizadores e educativos da sociedade (O DEBATE, 1914, p.2).

\section{Espaços teatrais em Mato Grosso}

O primeiro palco teatral em Mato Grosso foi o teatro São João, localizado na Rua Bella Vista, na cidade de Cuiabá (A GAZETA, 1889b, p. 4). No ano de 1889, este mesmo edifício foi vendido à sociedade dramática particular "Amor à Arte" e passou a se chamar Teatro Minerva (GAZETA OFICIAL, 1890c, p. 3; GAZETA OFICIAL, 1890e, p. 4).

Em setembro de 1894, um grande imprevisto é noticiado pelo jornal O Matto Grosso (1894a, p. 1), o prédio do Teatro Minerva desabara, deixando alguns cidadãos mato-grossenses desolados. O descontentamento ficou ainda mais evidente pois a recém-chegada "Companhia Teatral Espanhola do Sr. Velasco" à cidade de Cuiabá, inevitavelmente com a queda do prédio, tivera que aguardar por vários dias até que pudessem se apresentar. Neste ínterim, o salão da Segunda Escola do Sexo Masculino do I Distrito fora cedido e adaptado àquela companhia para estrear seus números (O MATTO GROSSO, 1894a, p. 2; O MATTO GROSSO, 1894b, p. 1).

Ainda em 1894, O Matto Grosso (1894c, p. 2) mencionou um outro espaço, o teatro Cuiabano, onde ocorrera um espetáculo de gala em homenagem ao presidente do Estado, na 
época, o Sr. Manoel José Murtinho. Contudo, as diversas reclamações divulgadas na nota com o espaço improvisado indicaram que este teatro ainda se tratava da escola adaptada para as apresentações da "Companhia do Sr. Velasco" (O REPUBLICANO, 1896b, p. 1).

Em 1917, o teatro Minerva finalmente foi arrendado para os Srs. Curvo e Irmãos passando a se chamar Cine Parisien (O MATTO GROSSO, 1917a, p. 1). Com este arrendamento, a imprensa manifestou possibilidades de melhoras em relação ao prédio, exceto o jornal $\mathrm{O}$ Pharol que acabou desabafando que Cuiabá estaria condenada a barracões desabrigados e escuros (O PHAROL, 1909b, p. 2).

Ainda que as fontes tenham revelado que os espaços mais utilizados para as representações teatrais em Mato Grosso eram os "barracões" verificou-se também que estes não eram os únicos. As sociedades teatrais ou agremiações particulares e amadoras também alugavam casas, ou até mesmo salões paroquiais para oferecer seus espetáculos (OASIS, 1894, p. 3).

A cidade de Poconé, apesar de pequena, também foi tomada como exemplo no universo teatral. Em 1909. O Pharol (1909c, p. 1) confirma a existência de um teatro confortável na cidade e, ainda, questiona o fato de Cuiabá sendo a capital não ter um tal qual aquele.

Em Corumbá, constatou-se que somente em 1909 o Poder Executivo Municipal concedera, gratuitamente, a Gregório dos Santos Barros um terreno para a construção de um teatro (O BRAZIL, 1909, p. 3).

Logo em 1911, a imprensa revela a instalação, já de algum tempo, de uma casa de diversões situada à Rua Lamare com nome de Polytheama Moderno. Não se descarta a possibilidade de se tratar aqui do teatro que fora construído no terreno concedido ao $\mathrm{Sr}$. Gregório, pelo Poder Municipal; esta hipótese é levantada pois ambos eram localizados na Rua Lamare em Corumbá. A nota descreveu ainda que este teatro, no mesmo ano de 1911, recebera uma reforma e passara a se chamar Bijou Teatro (CORREIO do ESTADO, 1911, p. 2). Talvez por não considerar essa mudança de nome, Siqueira (2002) diz que o Bijou Teatro foi fundado em 1919 e que o espaço atendia tanto apresentações teatrais, quanto cinematográficas, com palco suficiente para companhias de operetas, zarzuelas e comédias. Diz ainda que, o teatro tinha capacidade para 500 lugares e era enfeitado com 34 ricos camarotes e galerias.

Em 1919, outro espaço em Corumbá também ocupou as páginas dos jornais junto ao Bijou Teatro: o Cine Excelsior. Este espaço pareceu estar mais limitado a apresentações cinematográficas. Em 1927, mais um espaço teatral em Corumbá é mencionado pela imprensa, o teatro do colégio Imaculada Conceição (O PEQUENO MENSAGEIRO, 1927, p. 3). 
Na cidade de Cáceres, em 1926, o jornal A Razão revelou que a cidade também possuía um espaço destinado às representações teatrais e cinematográficas, o Cine Phenix (A RAZÃO, 1926, p. 2). Segundo Arruda (2002), os acontecimentos sociais, as peças de teatro e os pequenos concertos que aconteciam em Cáceres eram muito divulgados e aconteciam no Cine Phenix.

Em Campo Grande, ao que tudo indicou, foi o Trianon o seu primeiro espaço teatral. Adicionalmente, aparecem barracões ou casas alugadas, como já visto nas cidades de Cuiabá e Corumbá. Situado à Rua 14 de Julho, este espaço oferecia à sociedade espetáculos teatrais, filmes e ainda cedia seu espaço para reuniões e aulas de música (JORNAL DO COMMÉRCIO, 1923, p. 2).

Outro espaço também foi mencionado no ano de 1928 em Campo Grande, o Cine-Teatro Santa Helena. A princípio, parecia ser o mesmo espaço do Trianon que recebera uma reforma, mas, conforme outras referências, percebeu-se que este segundo localizava-se em outro endereço (JORNAL DO COMMÉRCIO, 1928c, p. 4).

Registros foram encontrados revelando que algumas companhias que saíam de Campo Grande seguiam para as cidades de Ponta Porã, Aquidauana e Miranda (JORNAL DO COMMÉRCIO, 1927b, p. 2). No entanto, nada foi exposto sobre quais espaços foram ocupados para as representações teatrais nestas cidades. Algumas possibilidades podem ser levantadas, por exemplo, salões paroquiais, casas familiares ou ainda barracões adaptados como já era de praxe em outras cidades.

Em Três Lagoas, o Cine Odeon foi quem se destacou na imprensa. Além de apresentações cinematográficas, o espaço também recebia companhias vindas de outros estados (GAZETA DO COMMÉRCIO, 1925, p. 4). João M. Spiridião, supostamente um empresário do ramo, era o dono do Cine Odeon e no ano de 1928 investiu também em outras cidades matogrossenses; comprou o Trianon Cine na cidade de Campo Grande e também o Cine Excelsior em Corumbá (JORNAL DO COMMERCIO, 1928, p.1).

Supõem-se que o teatro tornou-se algo promissor para o mercado de entretenimento a partir da década de 1920; o interesse do público e da imprensa por essa prática acabou despertando o interesse de empresários como foi o caso deste cidadão mato-grossense João M. Spiridião que investiu seu capital em várias cidades acreditando possivelmente num retorno com lucros significativos.

A cidade de Ladário também tinha seu espaço teatral; o jornal Tribuna, da cidade de Corumbá trouxe informações de uma homenagem da Marinha e afirma que este evento aconteceria no teatrinho N. S. dos Remédios, em Ladário, em junho de 1928 (TRIBUNA, 1928, p. 4). 
O teatro pareceu mesmo chamar a atenção a partir da década de 20 , além dos empresários como já visto, constatou-se também o interesse dos colégios neste ramo do entretenimento, como Lyceu Cuiabano, São Gonçalo em Cuiabá, Santa Tereza e Imaculada na cidade de Corumbá (AUTONOMISTA, 1908b, p. 1).

As notícias mostraram que as companhias que visitavam as cidades mato-grossenses arrendavam por tempo determinado os espaços que eram utilizados para as representações teatrais (O MATTO GROSSO, 1918b, p. 2). Esta informação é mais um indício de que o teatro tornara-se um investimento cujo retorno financeiro era atrativo.

Mais um fato revelado é que todos os espaços teatrais eram particulares. Serviam também como sedes para outras atividades que aconteciam nas cidades, como conferências públicas, conferências sobre assuntos da atualidade e religião, reuniões do partido republicano e até mesmo, bailes promovidos por alguns clubes (O MATTO GROSSO, 1890a, p. 2)

No discurso da imprensa, a infraestrutura teatral em Mato Grosso ainda era muito incipiente. De acordo com O Pharol (1909a, p. 4) "não existiam assentos no salão do teatro, as cadeiras tinham que ser levadas de casa com certa antecedência e, tinham que ser retiradas no outro dia conforme horário marcado".

\section{Instituições teatrais amadoras em Mato Grosso}

Neste período pareceu ser bem comum instituições amadoras intituladas como "sociedades" e/ou "grêmios" exercitarem práticas de diversão com diversas finalidades no estado de Mato Grosso, desse modo.

Uma sociedade que muito se destacou em Cuiabá, foi a “Amor à Arte". Esta instituição segundo Silva (2010) surgiu no ano de 1877. A imprensa confirmou este fato quando anunciou que "em agosto de 1890 uma grande festa foi realizada em comemoração ao seu 13o aniversário" (O MATTO GROSSO, 1890e, p.3).

Chamada de "Euterper Cuyabana" em sua razão social, a sociedade "Amor à Arte" parece ter sido uma das instituições que sobreviveu por mais tempo em Cuiabá. Silva (2010), diz que, a "Amor à Arte" acabou em 1894 após o desabamento de seu teatro mas, segundo uma nota publicada, no ano de 1902, esta sociedade ainda seguiu oferecendo seus espetáculos (O PHAROL, 1902, p. 2).

Outras sociedades também marcaram este período em Cuiabá, a "Escola Dramática” foi uma delas. Seus atores também eram amadores locais e chegaram inclusive a apresentar espetáculos junto à sociedade "Amor à Arte" (O MATTO GROSSO, 1898b, p. 3). A "Escola 
dramática" segundo Silva (2010), surgiu em 1893 e encerrou suas atividades três anos depois. No entanto, até o ano de 1898, os jornais ainda anunciaram espetáculos apresentados por esta instituição, bem como eleições para a escolha da sua nova diretoria (O REPUBLICANO, 1898a, p.4)

Em outubro de 1908, em Cuiabá, surge uma nova instituição amadora, o grêmio "Appollo" (O PHAROL, 1908, p. 3). Essa instituição segundo o mesmo jornal, continuou existindo no ano de 1909. Nada mais foi encontrado durante um tempo, até que em 1918 uma última evidência revelou um espetáculo encenado no Cine Parisien pelo grêmio "Appollo" (O MATTO GROSSO, 1918a, p. 2).

Não se pode afirmar que estes amadores sobreviveram por todo esse tempo, ou que encerraram suas atividades de forma definitiva exatamente neste ano; mas, pode-se supor que tenham vivido momentos de efervescência e decadência ao longo desses dez anos ou até mais que isso, conforme sugere as fontes consultadas.

De acordo com Santos (2012), surge em 1909 em Cuiabá, o grêmio "Álvares de Azevedo". Esse grupo segundo a imprensa se tornou a principal atração da cidade e assim como os demais, utilizou o espaço do antigo teatro "Amor à Arte" para a apresentação se seus espetáculos. Apesar dessa explosão inicial, este grêmio também viveu pouco tempo; os registros indicaram que aproximadamente até 1912 (O MATTO GROSSO, 1912a, p. 2).

A companhia "São Luiz Gonzaga" foi outra instituição amadora que fez parte da história teatral em Cuiabá. Embora alguns indícios apontassem-na como uma companhia visitante na cidade, as fontes revelaram que ela fora uma instituição composta por ex-alunos salesianos e de famílias tradicionais cuiabanas (O MATTO GROSSO, 1919a, p. 7)

A sociedade "Recreio Dramático" foi uma das companhias que se destacou na cidade de Corumbá; particular e composta também por amadores, essa sociedade se apresentou em várias noites corumbaenses por volta de 1894 em seu próprio clube. Oferecia além de apresentações teatrais, soirées que duravam, como descreveram as fontes, até altas horas da madrugada (ECHO DO POVO, 1894a, p. 2).

No ano de 1894, surge mais uma sociedade em Corumbá, a sociedade "União Dramática" que alugara uma casa para a inauguração de seus espetáculos (OASIS, 1894. p.3). Em 1896 o mesmo jornal trouxe uma nota ainda elogiando um espetáculo da "Sociedade União Dramática", nele o redator aproveitou para desejar muitos anos de existência para o grupo de amadores (OASIS, 1896, p. 4). 
No ano de 1897, o jornal O Sertanejo (1897, p. 3) escreveu dizendo que o salão do teatro "União Dramática" ainda era utilizado pelo "Grêmio Familiar Corumbaense", nome também elogiado pelos jornais do período.

Após estes registros poucas informações sobre essas instituições foram encontradas nos jornais selecionados, isto acaba remetendo a ideia de que o tempo de sobrevivência das sociedades corumbaenses tiveram prazos curtos assim como as de Cuiabá. O jornal O Brazil fortaleceu a hipótese da decadência dessas instituições amadoras em curtos prazos quando disse no ano de 1903, que a sociedade corumbaense estivera a um longo tempo privada de diversões (O BRAZIL, 1903, p. 2). Apesar disso, é relevante pensar que esta informação pode representar muito mais um apelo dos jornais pelo teatro, do que uma realidade vivida pelos cidadãos matogrossenses.

Além das já descritas instituições amadoras, Corumbá contava também com as irmãs salesianas e o padre Antonio Malan para a organização de várias festas e representações teatrais nos colégios salesianos (AUTONOMISTA, 1908b, p. 1).

Em Campo Grande, os salesianos fundaram uma agremiação, o "Círculo Dramático Dom Bosco". O ano de sua fundação provavelmente foi o de 1924, pois O Jornal do Commércio (1927a. p. 4) publica sobre a eleição de uma nova diretoria e a comemoração do terceiro aniversário desta associação. Por volta de 1928, o teatrinho da "associação Dom Bosco" ainda anunciava seus trabalhos.

Notas sobre amadores na cidade de Ladário também foram registradas, segundo o jornal, estes amadores teriam apresentado um espetáculo teatral na sede do "Riachuelo" (CAPITAL, 1926. p.4). Conforme Dias (2017) este era o nome de uma reconhecida equipe de futebol da cidade de Corumbá.

\section{Desafios e superações das Instituições amadoras}

A partir dos estudos realizados sobre as instituições teatrais amadoras mato-grossenses, ficou evidente que a maioria delas tiveram momentos de auge no início e tão prematuramente entravam em decadência. A imprensa chegou a associar essa decadência à falta de um teatro descente, porém, analisando as fontes, outros desafios foram revelados.

De acordo com os estudos percebeu-se que, a manutenção e sobrevivência das associações e agremiações mato-grossenses esteve associada principalmente ao pagamento de mensalidades de seus sócios e às cobranças de ingressos das peças (GAZETA OFICIAL, 1890a, 
p. 4). Supõe-se que essas instituições amadoras tinham como sócios as mais selecionadas pessoas da elite mato-grossense.

Em Mato Grosso, assim como em São Paulo e Rio de Janeiro, estas sociedades e agremiações se fiavam exatamente num composto entre pagamento de sócios e arrecadação por meio de leilões, vendas de prendas, doações e quermesses (O REPUBLICANO 1896a, p. 3). As modalidades variavam de acordo com o tipo de festividade e agremiação (MORAES, 2014). As sociedades e agremiações mato-grossenses em alguns casos tinham também o apoio do Estado e chegaram a receber auxílios para realização de obras no teatro (GAZETA OFICIAL, 1890f, p. 5).

A falta de sócios certamente causaria danos para essas instituições pois, as mensalidades assumidas por eles, pareceu ser um dos principais meios de manutenção financeira dessas sociedades, indicando neste caso, que o volume dos recursos arrecadados dependia do poder de organização dessas instituições, isto é, do número de associados que conseguiam angariar, do perfil socioeconômico desses membros e por fim, das peças produzidas e apresentadas (MORAES, 2014).

A partir da configuração da sociedade "Amor a Arte" foi possível conhecer mais sobre a organização dessas instituições amadoras; seus sócios elegiam entre seus membros alguns cargos como: presidente, vice-presidente, primeiro-secretário, segundo-secretário, diretor de cena, tesoureiro, procurador 1 e procurador 2, entre outros (GAZETA OFICIAL, 1890c, p. 3). As escolhas desses membros eram realizadas por meio de eleições anuais entre os próprios sócios, podendo acontecer no primeiro dia de cada ano ou então em casos excepcionais, como a saída de um desses representantes (GAZETA OFICIAL, 1890g, p. 3).

Constatou-se que essas sociedades e agremiações não conseguiam sobreviver por muito tempo, buscavam ajuda, realizavam festas em benefício próprio, mas acabavam encerrando em curtos prazos os seus trabalhos (GAZETA OFICIAL, 1890f, p. 5). Ainda assim, é importante reforçar que estas instituições cumpriam papéis importantes em relação a diversão. Vale ainda dizer que assim como no estado de Mato Grosso, no Rio de Janeiro, a então capital federal da época, e em São Paulo, também eram muito comum a exibição de peças teatrais organizadas por associações e agremiações amadoras e que os desafios enfrentados por estas não eram tão diferentes dos desafios vividos pela realidade mato-grossense (FRANCA, 2011).

\section{As Companhias Itinerantes}


Além das instituições amadoras e particulares, Mato Grosso também recebeu visitas de companhias que se instalavam por tempo determinado nas cidades. Os espaços eram cedidos ou alugados para que essas companhias executassem suas funções, na maioria das vezes aconteciam nas noites de sábado e de domingo (GAZETA OFICIAL, 1890b, p 4; AUTONOMISTA, 1908b, p. 1; O MATTO GROSSO, 1917d, p.3).

As companhias equestres fizeram parte desse repertório de visitantes em Mato Grosso. Em 1891, os jornais registraram na cidade de Cuiabá a chegada da "companhia do Senhor Arellano". As peças foram apresentadas no teatro Minerva (O MATTO GROSSO, 1891, p. 3).

A “companhia do Sr Velasco" também visitara Cuiabá. Sua chegada fora um tanto quanto tumultuada, pois coincidiu com a queda do único teatro da cidade no ano de 1894 . Apesar disso, permaneceu no local e aguardou até que um espaço improvisado pudesse ser disponibilizado para a apresentação de suas funções (O MATTO GROSSO, 1894b, p. 1).

Em janeiro de 1903, na cidade de Corumbá, o jornal O Brazil, registrou a chegada da companhia coordenada pelo "S. Carisi Dobler Hermínio". A expectativa da imprensa foi grande, acreditaram que a companhia traria à cidade passatempos agradáveis e atraentes $(\mathrm{O}$ BRAZIL, 1903, p. 2).

A “companhia Citá de Milano" também aparentemente proporcionou momentos de muita diversão à população corumbaense no ano de 1912. O jornal O Debate (1912,p.1), além de elogiar suas apresentações destacou que após a ordem do intendente Municipal a companhia organizara uma matinê para a criançada das escolas públicas no Bijou Teatro.

O Matto Grosso (1912b, p. 1) revelou também, que na cidade de Corumbá em 1912 uma “companhia de Óperas e Operetas"3. O periódico não diz o nome da tal trupe, apenas anunciou a chegada da mesma junto com seus 53 integrantes e complementou que a estreia acontecera no Bijou Theatre.

As informações divulgadas pela imprensa não foram capazes de dizer o tempo de permanência dessas companhias nas cidades mato-grossenses, mas é razoável dizer que eram bem breves, a exemplo da "companhia do Sr Carisi Dobler Hermínio" que em janeiro de 1903 apresentou-se na cidade de Corumbá e em fevereiro do mesmo ano já anunciava seus espetáculos em Cuiabá (O PHAROL, 1903b. p.3). Vale lembrar que neste intervalo de tempo incluiu-se o deslocamento entre essas duas cidades que por sinal, era realizado apenas por navegação fluvial (MARTINS, 2000).

\footnotetext{
${ }^{3}$ De acordo com Rodrigues (2008), "opereta" é um gênero teatral vindo da França, composto por cançonetas, cenas cômicas, duetos cômicos. Baseados na alegria, na música ligeira, na malícia e na beleza das mulheres. No Brasil este gênero chegou no início dos anos 1860.
} 
A trupe artística sob a direção de "Arturo Ricart" foi outra companhia que visitou a sociedade cuiabana em 1913 e acabou se destacando entre os jornais da cidade (O DEBATE, 1913, p. 2).

$\mathrm{O}$ registro de mais uma companhia chegando à cidade foi feito pelo jornal $\mathrm{O}$ Matto Grosso em Cuiabá no ano de 1917. A companhia era portuguesa e se instalou no Cine-teatro Parisien e por lá permaneceu por vários dias (O MATTO GROSSO, 1917b, p.5).

Pelos palcos cuiabanos passou ainda em 1918 o "Sr. Nilo Durval”, um transformista, cuja especialidade, era imitar o que eles denominavam, naquela época, de sexo fraco ou belo sexo (O MATTO GROSSO, 1018c, p. 2). Estes termos pareciam ser utilizados na época, para caracterizar o sexo feminino.

No mesmo ano de 1918 passou também por Cuiabá a "companhia Salvaterra", coordenada pelo ator português Raphael Salvaterra. Essa companhia, segundo o jornal A Cruz, trouxera peças mais ousadas, causando incômodo para alguns cidadãos (A CRUZ, 1918, p. 1).

Em 1919, a companhia “Alzira Leão” chegou à Cuiabá. Conhecida também nas plateias cariocas, acabou sofrendo pressão pelo mesmo jornal católico A Cruz. As publicações acusaram o trabalho de indecentes e imorais (A CRUZ, 1918, p. 1; A CRUZ, 1919, p. 1). O Matto Grosso (1919b, p. 2) entretanto, prestigiou os seus espetáculos e enfatizou que com a chegada desta trupe, a monotonia de dias insípidos com tão poucas diversões poderia ser quebrada.

No ano de 1925, em Três Lagoas, chegou a popular companhia do senhor "Santos e Silva e Esposa”. Os seus espetáculos apresentados no Cine Odeon foram de muitos elogios nas páginas da imprensa (GAZETA DO COMMERCIO, 1925, p. 4).

Em Cáceres, já no ano de 1926, o jornal A Razão registrou a chegada do Sr. Levino Albano, um violinista cego, muito famoso que chegara a cidade para ajudar a quebrar a monotonia em que viviam os cacerenses, como descreveu a fonte (A RAZÃO, 1926, p. 2).

Em 1928, viajara também pelas cidades mato-grossenses a companhia "Conceição Ferreira". O primeiro registro mostrou a chegada da companhia na cidade de Cuiabá, onde fora muito elogiada (O MATTO GROSSO, 1928b, p. 2). Em seguida eles se apresentaram em Campo Grande e, mais precisamente no dia 27 de novembro, O Jornal do Commércio (1928b, p. 1) publicou sua despedida da cidade, no Cine-Teatro Santa Helena.

A chegada de trupes circenses também foram registradas nas cidades mato-grossenses com espetáculos variados de dramas e comédias, ginásticas, atividades equestres à encenações teatrais (O MATTO GROSSO 1904a, p. 3; O MATTO GROSSO 1904b, p. 1). Contudo, o circo na visão da imprensa era tido como uma diversão ingênua e estava longe de se tornar um alvo 
dos discursos racionalizadores da época. "Aparece em seu descomprometimento com o real e o provável, em sua barbárie e em seu nomadismo (DUARTE, 1993)”.

No discurso da imprensa o teatro sim estava atrelado a ideais de progresso, inclusive chegaram a divulgar que "a capital já não era tão pequena e já havia conquistado inclusive alguns elementos de progresso, merecendo inclusive um teatro condigno dos seus foros" (O REPUBLICANO, 1896b, p. 1).

Constatou-se portanto que muitas companhias passaram pelas cidades mato-grossenses. De certa forma, as publicações recorrem às companhias que mais se destacaram ou as que de alguma forma causaram certas provocações no meio social. O trabalho de leitura e análise dessas fontes permitiu também observar que o tempo entre uma companhia e outra percorrendo as cidades mato-grossenses era bem longo. Em muitas notícias os jornais mostraram e questionaram esse grande espaço de tempo sem visitas de companhias teatrais no estado e associaram esta ausência à falta de estrutura dos prédios cedidos para as representações teatrais. A maior indignação se deu na capital Cuiabá, pois apesar de representar o estado, a cidade, segundo eles, ainda não possuía um teatro oficial, somente barracões velhos e escuros (O PHAROL, 1909c, p. 1).

\section{As Peças Teatrais em Mato Grosso}

As peças teatrais em Mato Grosso, no período entre 1877 e 1928, ficaram sob responsabilidades das instituições amadoras e das companhias itinerantes que passavam pelo Estado. Baseadas na maioria das vezes no teatro europeu, as influências portuguesas e francesas eram fortes e os enredos dessas peças, de modo geral, tinham um caráter que instruísse aos princípios cristãos católicos, baseados na Bíblia.

Cobranças da imprensa com princípios cristãos nos enredos das peças ficaram evidentes em diversos momentos. Numa nota do jornal A Cruz (1919, p. 1) por exemplo, foi possível verificar a insatisfação dos mesmos com os trabalhos de algumas companhias itinerantes. Segundo eles "a moral dos mato-grossenses teria sido enxovalhada em algumas apresentações para a alegria dos libertinos e vergonha das famílias" (A CRUZ, 1918, p. 1) Complementaram ainda que "receberam queixas e depoimentos, vindo de famílias cuiabanas, questionando a imoralidade exibida no Parasien. Embora a imprensa tenha compartilhado diversas cobranças como esta, não é certo generalizá-las, visto que outros jornais descreveram com naturalidade os mesmos trabalhos. 
Era comum que os elementos utilizados na construção dos enredos das peças se mesclassem entre o sagrado e o profano, buscando por meio das representações dominar a sociedade. De acordo com Silva (2010), os temas tratavam de questões sociais contemporâneos à época, porém, o que pareceu, foi que essas questões não estavam atreladas à cultura local, e sim, às situações mais próximas dos países europeus.

Em meados do século XIX, na literatura, acontecia uma transição do Romantismo para o Realismo e no teatro uma mistura desses elementos também se fez presente, principalmente no que se referiu aos enredos das peças. Os temas começaram então a tratar de assuntos polêmicos como a escravidão na tentativa de chamar a atenção da sociedade (FARIA, 2013). Neste ínterim muitos escritores engajaram-se na escrita de peças genuinamente brasileiras. Isso contribuiu para que Mato Grosso tivesse os primeiros contatos com peças nacionais. O estado passou então a ter oportunidades de conhecer novos enredos escritos também por autores nacionais, e aos poucos, foi ocorrendo a inclusão de elementos da cultura local nas peças (SILVA, 2010).

Entre os gêneros das peças teatrais em Mato Grosso, destacou-se de início os dramas e as comédias. Escritos por franceses como Eugène Labriche e Ernest Legouvé, por portugueses como Silva Braga e José da Silva Mendes Leal, por brasileiros como Horácio Nunes e Artur Azevedo, dentre outros. (AUTONOMISTA, 1908a, p. 2; GAZETA OFICIAL, 1890a, p. 4; NUNES, 2014; NEVES, 2006) Essas peças foram atrações não só em Mato Grosso mas também em outros estados como no Rio de Janeiro (O MATTO GROSSO, 1919c, p.3). Também fizeram parte do repertório de peças em Mato Grosso as operetas. A presença deste gênero na cidade cuiabana fortaleceu a ideia sobre as influências francesas em temas e enredos de trabalhos mato-grossenses. Este gênero segundo a imprensa agradou o público da cidade $(\mathrm{O}$ MATTO GROSSO, 1894c, p. 2).

Os jornais revelaram também dentre as peças mato-grossenses, o "vaudeville". Este gênero ficou conhecido como espetáculos teatrais e de divertimento que eram apresentados nas feiras sazonais de Paris. Essas feiras recebiam espetáculos como domadores de feras, gigantes, anões, malabaristas, dançarinos de corda bamba, os quais foram dando lugar, ao passar do tempo, a pequenas comédias em prosa ou verso entremeadas por música, ou seja, um teatro de variedades. Por volta da segunda metade do século XVII, esse tipo de espetáculo foi ganhando um caráter mais homogêneo e essas pequenas peças foram se estruturando e passaram a utilizar como parte musical, paródias de árias ou canções conhecidas pelo público (SCANDAROLLI, 2012). Este gênero alcançou muito sucesso também entre o público carioca (O MATTO GROSSO, 1917b, p. 4). 
A zarzuela, foi outro gênero teatral prestigiado pelos mato-grossenses neste período. Considerado uma obra dramática e musical de origem espanhola, é reconhecida como uma espécie de ópera cômica, na qual alternadamente, se declama e se canta. O gênero também pareceu agradar, de acordo com os comentários feitos pela imprensa, os mato-grossenses aplaudiram e presentearam os atores (RODRIGUES, 2008).

O teatro de revista foi bastante utilizado pelas companhias visitantes em Mato Grosso entre 1877 e 1928 (O MATTO GROSSO, 1917c, p. 3). Este gênero se caracteriza como um veículo de difusão de modos e costumes, como um retrato sociológico, ou como um estimulador de riso e alegria através de falas irônicas e de duplo sentido, canções apimentadas e hinos picarescos. Contém elementos como a dança, os versos, a comédia musicada, entre outros. O teatro de revista conta com um clima alegre, descontraído e, ao mesmo tempo revela a hipocrisia da sociedade (PAIVA, 1991).

A revista em prólogo também foi citado pela imprensa. Segundo a nota, este gênero ainda não era conhecido em Cuiabá, mas os relatos foram de satisfação, entusiasmo, e até solicitações de reprises de diversos números (O MATTO GROSSO, 1917c, p. 3).

Nem todas as peças apresentadas em Mato Grosso tinham informações acerca do gênero ou enredo das mesmas, ainda assim, ficou claro o desejo da imprensa em atribuir fins educativos, civilizatórios e moralistas ao teatro. Conforme o discurso da imprensa, o teatro não era apenas uma diversão, era também um espaço onde se pudesse conhecer e compreender sobre conflitos políticos, sociais e até mesmo raciais (O MATTO GROSSO, 1928a, p. 1).

\section{A Plateia Chegou! O Público quer Teatro}

O público foi algo que chamou atenção no processo de análise das peças pois, na maioria das vezes, os espaços eram descritos pela imprensa como lotados ou com pouca disponibilidade de lugares à venda. Numa nota do jornal A Gazeta $(1889$, p. 4) subintende-se quando dizem que "alguns dos ingressos que ainda existiam deveriam ser procurados pelo thesoureiro da sociedade “Amor à Arte”” (A GAZETA, 1889b, p. 4).

As peças teatrais eram quase sempre anunciadas pela imprensa, isso leva a pensar que o público que frequentava o teatro tinha acesso a estes periódicos, podendo se atualizar com as programações oferecidas nas cidades. Deste modo, os primeiros registros encontrados sobre o público presente nas apresentações teatrais em Mato Grosso e divulgados pela imprensa foram de ex-estudantes de escolas renomadas, tanto de cidades mato-grossenses como de outros 
estados, como fora o caso do estudioso acadêmico Luiz Serra, vindo de São Paulo (O MATTO GROSSO, 1890c, p. 2).

Além destes, os políticos e oficiais da polícia apareceram como outra classe que sempre frequentavam o teatro. A imprensa, no ano de 1894 anunciou um espetáculo de gala e revelou que naquela simpática festividade compareceram além do Sr. Dr. Presidente e sua família, distintos cavalheiros, famílias da sociedade cuiabana, representantes de diferentes classes sociais e ainda, diversas autoridades civis e militares (O MATTO GROSSO, 1894c, p. 2).

Em Corumbá, também no ano de 1894, notou-se que os espetáculos da sociedade Recreio Dramático só permitiram como espectadores os seus próprios sócios e eventuais convidados, como mostra O jornal Echo do Povo (1894b, p. 4), "avisa-se aos Srs. Sócios, que são obrigados a apresentarem o cartão de ingresso a pessoa que esteja na portaria nos dias de espetaculo, afim de evitar o ingresso de estranhos e não convidados".

Em Cuiabá, o acesso aos espetáculos organizados pelas sociedades amadoras pareceu ser diferente. Segundo o jornal O Matto Grosso (1898b, p. 3) as sociedades "Amor à Arte" e "Escola Dramática” organizaram um evento e fizeram questão de convidar não só os sócios como também todas as famílias e cavalheiros da sociedade.

Contudo é importante destacar que políticas diferenciadas foram adotadas por outras instituições amadoras em Corumbá, a exemplo o Clube Treze de Junho que apesar de ter utilizado o espaço teatral da sociedade Recreio Dramático para apresentação de um espetáculo, abriu as portas para toda a sociedade corumbaense e conforme fora divulgado na imprensa, "apesar do calor sufocante o espaço do Recreio Dramático tava repleto de expectadores" (A FEDERAÇÃO, 1898, p. 2).

Na cidade de Cuiabá, no ano de 1898, o jornal O Matto Grosso trouxe mais dados sobre o público que se fizera presente num outro espetáculo oferecido pela sociedade "Amor à Arte". O responsável pela nota, num pequeno trecho revelou quais espectadores estiveram presentes neste evento.

O que sei é que grande cuncorrência de espectadores, apresentava um quadro deslumbrante de tudo quanto a sociedade cuyabana tem de destincto; na imprensa, nas letras, no commercio, na... ia dizer na lavoura; cousa que aqui não há; enfim, tirando-se alguns compradores de borrachas, que mesmo não frequientam essas coisas, a melhor sociedade cuyabana estava reunida no recinto, onde ia ser levado á secna o mais pyramidal espectaculo visto desde o primeiro dia do anno de graça de 1898 (O MATTO GROSSO, 18998a, p. 3)

Claramente percebe-se um público elitizado, levando em consideração ora o nível intelectual, ora o poder aquisitivo, os compradores de borracha por sua vez, pareceram ser vistos pela imprensa com certo estranhamento e repulsão nos ambientes teatrais mato-grossenses. 
Os representantes dos jornais também podem ser acrescentados como parte do público teatral de Mato Grosso. Em algumas notícias, inclusive, estes cidadãos fizeram questão de agradecer aos convites enviados pelas companhias visitantes ou mesmo instituições amadoras (O MATTO GROSSO, 1911, p. 2). Neste caso, não se pode descartar a ideia de que estes convites pudessem ser realizados com determinados interesses como: divulgação de trabalhos, ou quem sabe a pagamentos de cachês para publicações tendenciosas supervalorizando as peças. Estas ações poderiam contribuir de certo modo num maior número de espectadores frequentando o teatro.

O jornal O Commércio da cidade de Campo Grande destacou que entre o público teatral mato-grossense estiveram também alguns senhores, que segundo o periódico, tinham o desplante de incendiar grossos charutos, cigarros e até cachimbos durante a sessão teatral; também mulheres com crianças de peito que causavam constante irritação de nervos no restante da plateia quando seus pimpolhos começavam a berrar igual bezerro desmamado. $\mathrm{O}$ jornal mostra indignação pelas mães que nada faziam e questionam essas mulheres por não se retirarem do espaço (JORNAL DO COMMÉRCIO, 1928a, p. 1).

Este cenário recorre à hipótese de um público pertencente a uma camada social mais elevada que então teriam condições de desfrutar de alguns vícios como o charuto e até mesmo ostentá-lo durante as sessões teatrais. As mulheres com crianças de colo provavelmente apresentavam também boas condições financeiras, no mínimo um meio de locomoção confortável para realizar o trajeto de casa ao teatro, eventualmente o bonde. Cabe aqui ressaltar que alguns jornais citaram-nos como opção de transporte.

Numa apresentação teatral organizada pelos salesianos foi publicado que após o espetáculo haveria bondes, pelo preço de costume (O PHAROL, 1903a, p. 2). Os preços não foram revelados pela imprensa, ainda assim, recorda-se que este meio de transporte era uma das únicas opções nas cidades mato-grossenses até meados de 1918, especialmente na capital.

Sobre valores dos ingressos para o teatro neste período, evidenciou-se que em média o camarote com seis entradas custava $6 \$ 000$ (seis mil reis), as cadeiras numeradas: $3 \$ 000$ (três mil reis), os bancos: $2 \$ 000$ (dois mil reis) e um espaço denominado como geral: $\$ 500$ (quinhentos reis) (GAZETA OFICIAL, 1890a, p. 4). Estas informações mostraram a existência de plateias diferenciadas dentro do mesmo espaço teatral.

Para reforçar a ideia de que frequentar o teatro mato-grossense não era algo tão acessível na época, recorreu-se aos anúncios da imprensa com valores pagos pela sociedade para aquisição dos mantimentos utilizados no cotidiano. Percebeu-se então que estes eram semelhantes aos valores dos bilhetes de entrada do teatro. Entre esses produtos, destacou-se lata 
de querosene brilhante $7 \$ 000$ (sete mil reis), vassoura de cabelo para assoalhada: $2 \$ 500$ (dois mil e quinhentos reis), vassoura de palha encorpada: $\$ 160$ (cento e sessenta reis), tubo de vidro para lampião de querosene: $\$ 400$ (quatrocentos reis), papel encorpado para oficio resma: $4 \$ 500$ (quatro mil e quinhentos reis), pimenta do reino kg: 1 \$500 (mil e quinhentos reis), macarrão e outras massas: $1 \$ 400$ (mil e quatrocentos reis) entre outros (O MATTO GROSSO, 1890d, p. 4).

Obedecendo às proporções dos custos destes produtos, pôde-se ter uma noção do quanto as pessoas pagavam para ir ao teatro. Segundo Souza, parte da população trabalhadora neste período recebia salários que giravam em torno de $1 \$ 500$ (mil e quinhentos reis) a diária (SOUZA, 2008). Este valor era quase o equivalente ao preço do macarrão ou ainda a uma única entrada no teatro da cidade.

Deste modo, ainda que a imprensa pudesse condenar outras formas de diversões tidas como proibidas ou pouco civilizadas, era comum que estes trabalhadores, fosse pela falta de recursos ou pela própria afinidade, constituíssem outros espaços de sociabilidade como corridas de burros em plena avenida, banhos nus às margens do rio nas regiões portuárias e até mesmo as touradas que apresentavam valores de acesso bem inferiores aos do teatro (SOUZA, 2008).

Apesar de algumas evidências de um público seleto frequentando o teatro matogrossense, não se pode descartar que pessoas menos favorecidas financeiramente também fossem ao teatro. Deve-se levar em conta que os jornais podiam ser tendenciosos e revelariam apenas as informações que eles julgavam importantes para si próprios e/ou a determinados grupos.

\section{Considerações Finais}

Para conhecer o universo teatral em Mato Grosso a imprensa periódica foi a principal porta de entrada, pois se mostrou presente em todos os acontecimentos políticos, econômicos, sociais, culturais, administrativos e mercadológicos das cidades mato-grossenses no período estudado e, ainda que não totalmente imparcial, as notícias deixaram vestígios da realidade vivida por diferentes grupos sociais.

Ao que tudo indicou, entre os anos de 1877 a 1928, os espaços destinados às representações teatrais em Mato Grosso eram todos particulares, e os responsáveis recebiam, vez ou outra, auxílios para manutenção ou reforma de órgãos públicos municipais ou estaduais. Serviram também como sedes para outras atividades que aconteciam nas cidades, como 
conferências públicas, conferências sobre assuntos da atualidade e religião, reuniões, bailes, dentre outros.

Entre as instituições amadoras, a sociedade Amor à Arte ocupou significativamente as páginas dos jornais locais, mas além dela, outras também fizeram parte da história teatral de Mato Grosso e enfrentaram situações parecidas como falta de recursos, e dificuldades de sobrevivência.

Além das instituições amadoras, companhias itinerantes se apresentavam em Mato Grosso, arrendavam por tempo determinado os espaços teatrais e por alguns dias permaneciam nas cidades. As peças teatrais se concentraram principalmente nas cidades de Cuiabá e Corumbá. Aos poucos, começaram também a serem mencionadas pela imprensa as cidades de Cáceres, Campo Grande, Três Lagoas, Ladário e outras.

Os conteúdos levados em cena em Mato Grosso foram praticamente os mesmos sucessos de grandes palcos das cidades do Rio de Janeiro e São Paulo, isso talvez tenha acontecido pela baixa quantidade de escritores do próprio estado neste período.

Um bom número de peças portuguesas e francesas fora registrado neste período em Mato Grosso, além de algumas espanholas e italianas. Estas peças foram representadas por grupos amadores ou companhias profissionais que visitaram algumas cidades do estado.

Mesmo inspirando-se em autores europeus, os autores brasileiros tiveram iniciativas de criar seus enredos, valorizando os acontecimentos históricos e sociais vividos no próprio território brasileiro. Desta forma, o teatro no Brasil e consequentemente no Mato Grosso ganharam particularidades e conseguiram exibir enredos que retrataram as experiências próprias.

As comédias, os vaudevilles, as operetas, as zarzuelas e o teatro de revista fizeram parte do repertório de atrações teatrais em Mato Grosso neste período. Tanto as instituições amadoras quanto as companhias itinerantes utilizaram na maioria das vezes os enredos que abordavam situações cotidianas daquela sociedade.

Verificou-se que Mato Grosso estava bem próximo dos trabalhos vivenciados pela então capital federal, inclusive nas políticas de organização financeira das sociedades e agremiações teatrais. Apesar de sua localização geográfica mais distante do litoral, o que pareceu, era que o estado não estava tão isolado das práticas vivenciadas por outros estados do país.

O público que frequentava o teatro em Mato Grosso se mostrou bastante elitizado. Durante todo o período investigado, entre outros fatos, constatou-se que os valores cobrados pelos ingressos permaneceram constantes. Mantidas as proporções de custos e preços da época, estes ingressos pareceram razoavelmente caros para a realidade de muitos cidadãos. 
Houve indícios também de que a partir da década de 1920, os empresários matogrossenses pareceram vislumbrar o teatro como algo promissor para o mercado de entretenimento, como foi o caso do Sr. João M. Spiridião que era o dono do Cine Odeon em Três Lagoas e no ano de 1928 investiu também em outras cidades mato-grossenses neste mesmo ramo.

Pôde-se ainda identificar as principais formas de organizações teatrais no estado, bem como as diferentes maneiras que a sociedade se apropriou desta arte tida pela imprensa como uma prática de diversão civilizadora e educativa. Adicionalmente a pesquisa integra-se aos trabalhos historiográficos de Mato Grosso, valendo-se da perspectiva da imprensa local para revelar a interação dos principais elementos que compuseram o contexto teatral naquele período.

\section{Referências Bibliográficas}

A CRUZ. A Immoralissima Companhia Salvaterra e seus espetáculos no Parisien. Cuiabá: 15 de dezembro de 1918, ano IX, n. 407, p. 1.

A CRUZ. Cuiabá: 8 de junho de 1919, ano X, n. 430, p. 1.

A GAZETA. 13 de junho. Cuyabá: 20 de junho de 1889a, ano I, n. 41, p.1.

A GAZETA. Cuyabá: 1 de agosto de 1889b, ano I, n. 49. p.4.

A FEDERAÇÃ̃o. Club Treze de Junho. Corumbá: 30 de janeiro de 1898, ano 2, n. 66, p.2.

A NOTICIA. Programma das festividades da inauguração do Campo dos Escoteiros de Três Lagoas em 3 de Maio. Três Lagoas: 21 de abril de 1927, ano VII, n. 218. Entrante, p.4. AMARAL, Luiz. A mais linda viagem: Um "raid" de vinte mil kilometros pelo interior brasileiro. São Paulo: Editora Proprietária, 1927.

A RAZÃO. Cáceres: 29 de maio de 1926, ano X, n. 469. p.2.

ARRUDA, Adson de. Imprensa, vida urbana e Fronteira: A cidade de Cáceres nas primeiras décadas do século XX (1900-1930). (Dissertação Mestrado). Universidade Federal de Mato Grosso. Cuiabá: 2002.

AUTONOMISTA. Corumbá: 02 de maio de 1908a, ano III, n. 141. Folhetim, p.2.

AUTONOMISTA. Festa Salesiana. Corumbá:16 de maio de 1908b, ano III, n. 143, p.1.

AUTONOMISTA. Espectaculo. Corumbá:18 de junho de 1908c, ano III, n.147, p. 2.

CAPITAL. Á Capital de Corumbá. Cuyabá: 31 de agosto de 1926, ano III, n. 79, p. 4.

CORREIO DO ESTADO. Corumbá: 1 de junho de 1911, ano II, n. 184, p. 2.

DIAS, Cleber Augusto. Esportes nos confins da civilização: Mato Grosso, 1920-1930. In: Topoi, Rio de Janeiro: v. 18, n. 34, p. 66-90, jan./abr. 2017.

DIAS, José da Silva. Teatros do Rio: do Século XVIII ao Século XX . Rio de Janeiro: FUNARTE, 2012, p. 19.

DUARTE, Regina Horta. Noites Circenses - Espetáculos de circo e teatro em Minas Gerais no século XIX. (Tese de Doutorado). Campinas: Departamento de História do Instituto de Filosofia e Ciências Humanas da Universidade Estadual de Campinas, 1993.

ECHO DO POVO. Corumbá: 31 de março de 1894a, ano II, n. 59, p. 2.

ECHO DO POVO. Annuncios sociedade Recreio Dramático. Corumbá: 22 de abril de 1894b, ano II, n. 62, p. 4. 
FARIA, João Roberto. Teatro romântico e escravidão. In: Teresa - Revista de Literatura Brasileira $\{12 / 13\}$, São Paulo. p. 94-111, 2013. Disponível em: <http://www.revistas.usp.br/teresa/article/download/99061/97567>, acessado em: 27/10/2016. FRANCA, Luciana Penna. Teatro amador: a cena carioca muito além dos arrabaldes. (Dissertação de Mestrado). Instituto de Ciências Humanas e Filosofia da Universidade Federal Fluminense. Rio de Janeiro: 2011, 118p.

FRANCO; Gilmara Yoshihara. O binóculo e a pena: a construção da identidade matogrossense sob a ótica virgiliana: 1920-1940. Dourados: Editora da UFGD, 2019, p. 27.

GAZETA DO COMMERCIO. Companhia Santos Silva. Três Lagoas: 25 de outubro de 1925, ano VI, n. 232, p. 4.

GAZETA OFICIAL. Cuyabá: 10 de junho de 1890a, ano 1, n.15, p. 4.

GAZETA OFICIAL. Cuyabá: 01 de julho de 1890b, ano 1, n. 24. Annuncio, p. 4.

GAZETA OFICIAL. Cuyabá: 13 de julho de 1890c, ano 1, n. 30, p. 3.

GAZETA OFICIAL. Cuyabá: 09 de setembro de 1890d, ano 1, n. 54, p. 3.

GAZETA OFICIAL. Cuyabá: 04 de outubro de 1890e, ano 1, n. 65, p. 4.

GAZETA OFICIAL. Cuyabá: 20 de dezembro de 1890f, ano 1, n. 98, p. 5.

GAZETA OFICIAL. Sociedade P. Euterpe Cuyabana. Cuyabá: 30 de dezembro de 1890g, ano 1, n. 102 , p. 3.

JORNAL DO COMMERCIO. Trianon Cine. Seu arrendamento pela empreza Cinemtographica Odeon, de Três Lagoas. Três Lagoas: 6 de novembro de 1928, ano 8, n. 656, p. 1.

JORNAL O COMMÉRCIO. Campo Grande: 17 de janeiro de 1923, ano II, n. 87, p. 2.

JORNAL O COMMÉRCIO. Associação Dom Bosco. Campo Grande: julho de 1927a, ano 7, n. 270, p. 4.

JORNAL O COMMÉRCIO. Waldemiro Lobo. Campo Grande: 22 de setembro de 1927b, ano 7, n. 335, p. 1.

JORNAL O COMMÉRCIO. Campo Grande: 13 de junho de 1928a, ano 8, n. 541. Subscrevemos, p. 1.

JORNAL DO COMMÉRCIO. Campo Grande: 27 de novembro de 1928b, ano 8 , n. 672 , p. 1 .

JORNAL DO COMMÉRCIO. Campo Grande: 01 de dezembro de 1928c, ano 8, n. 676, p. 4. LOTT, Alcides Moura. Teatro em Mato Grosso - Veículo da dominação colonial. Brasília: Ed. Brasiliana, 1987, p. 26.

MARTINS, Moisés Mendes Jr. Revendo e Reciclando a Cultura Cuiabana. Cuiabá: Ed. Copyright, $2000 \mathrm{p}$.

MELO, Victor Andrade; ALVES JR, Edmundo de Drummond. Introdução ao Lazer. 2. ed. São Paulo: Editora Manole, 2012.

MORAES, Julio Lucchesi. Sociedades culturais, sociedades anônimas: Distinção e massificação na economia da cultura brasileira (Rio de Janeiro e São Paulo, 1890 a 1922).

(Tese Doutorado). São Paulo: Faculdade de Filosofia, Letras e Ciências Humanas da Universidade de São Paulo, 2014. p. 30.

NEVES, Larissa de Oliveira. As comédias de Artur Azevedo: em busca da história. (Tese Doutorado). Campinas: Instituto de Estudos da Linguagem da Universidade Estadual de Campinas. Unicamp/ FAPESP. 2006, p. 125.

NUNES, Horácio Pires. Anjo do Lar. (Peça Teatral). São Paulo: Poeteiro editor digital, 2014, Projeto Livro Livre, livro 316. Disponível em <http://www.santoandre.sp.gov.br/ pesquisa/ebooks/ 366864.PDF>, acessado em 10/10/2016.

OASIS. Corumbá: 26 de abril de 1894, ano 7, n. 268, p. 3.

OASIS. Homenagem. Corumbá: 31 de março de 1896, ano 9, n. 345, p. 4.

O BRAZIL. Corumbá: 18 de janeiro de 1903, ano 1, n. 17, p. 2. 
O BRAZIL. Corumbá: 02 de setembro de 1909, ano VII, n. 332, p. 3.

O DEBATE. Cuyabá: 18 de setembro de 1912, ano I, n. 292, Secção Telegráfica, p. 1.

O DEBATE. Triumvirato Humorístico. Cuyabá: 01 de maio de 1913, ano II, n. 469, p. 2.

O DEBATE. Cuyabá: 26 de abril de 1914, ano III, n. 757, Dominicaes, p. 2.

O PHAROL. Cuyabá: 23 de agosto de 1902, ano I, n. 17, p. 2.

O PHAROL. Theatro. Cuyabá: 07 de fevereiro de 1903a, ano I, n. 43, p. 2.

O PHAROL. Espectaculo. Cuyabá: 28 de fevereiro de 1903b, ano I, n. 46, p. 3.

O PHAROL. Cuiabá: 10 de outubro de 1908, ano IV, n. 167, p. 3.

O PHAROL. Cuiabá: 01 de maio de 1909a, ano IV, n. 196, p. 4.

O PHAROL. Cuiabá: 22 de maio de 1909b, ano IV, n. 199, p. 2.

O PHAROL. Cuiabá: 27 de novembro de 1909c, ano V, n. 225, p. 1.

O PEQUENO MENSAGEIRO. No Collegio Immaculada Conceição. Cuiabá: 24 de janeiro de 1927, ano X, n. 116, p. 3.

O MATTO GROSSO. Cuiabá: 26 de janeiro de 1890a, ano XII, n. 576, p. 2.

O MATTO GROSSO. Cuyabá: 23 de fevereiro de 1890b, ano XII, n. 579, p. 2.

O MATTO GROSSO. Cuyabá: 17 de junho de 1890c, ano XII, n. 593, p. 2.

O MATTO GROSSO. Grande Queima! Cuyabá: 20 de julho de 1890d, ano XII, n. 596, p. 4.

O MATTO GROSSO. Cuyabá: 25 de agosto de 1890e, ano XII, n. 603. p. 3.

O MATTO GROSSO. Cuyabá: 05 de março de 1891, ano XII, n. 617, p. 3.

O MATTO GROSSO. Cuyabá: 3 de setembro de 1894a, ano XVI, n. 755. pp. 1-2.

O MATTO GROSSO. Domingo a domingo. Cuyabá: 7 de outubro de 1894b, ano XVI, n. 757, p. 1.

O MATTO GROSSO. Espectáculo de Gala. Cuyabá: 21 de outubro de 1894c, ano XVI, n. 759, p. 2

O MATTO GROSSO. Palcos e Artistas. Cuyabá: 23 janeiro de 1898a, ano XX, n. 929 , p. 3.

O MATTO GROSSO. Cuyabá: 13 de março de 1898b, ano XX, n. 936, p. 3.

O MATTO GROSSO. Circo Palma no Teatro Amor à Arte. Cuyabá: 20 de março de 1904a, ano XXII, n. 1021, p. 3.

O MATTO GROSSO. Circo Sohá. Cuyabá: 31 de julho de 1904b, ano XXII, n. 1040 , p. 1.

O MATTO GROSSO. Theatro. Cuyabá: 24 de setembro de 1911, ano XXIII, n. 1103, p. 2.

O MATTO GROSSO. Cuyabá: 21 de julho de 1912a, ano XXIII, n. 1146, p. 2.

O MATTO GROSSO. Cuyabá: 25 de agosto 1912b, ano XXIII, n. 1150, p. 1.

O MATTO GROSSO. Cuyabá: 08 de março 1917a, ano XXVIII, n. 1389. p.3.

O MATTO GROSSO. Theatro. Cuyabá: 30 de agosto 1917b, ano XXVIII, n. 1431, p. 4.

O MATTO GROSSO. Theatros. Cuyabá: 06 setembro de 1917c, ano XXVIII, n. 1433 , p. 3.

O MATTO GROSSO. Theatro. Cuyabá: 18 setembro de 1917d, ano XXVIII, n. 1434, p. 3.

O MATTO GROSSO. Cuyabá: 26 de maio de 1918a, ano XXIX, n. 1492, p. 2.

O MATTO GROSSO. Cuyabá: 17 de outubro de 1918b, ano XXX, n. 1515, p. 2.

O MATTO GROSSO. Theatros e Cinemas. Cuyabá: 24 de Outubro de 1918c, ano XXX, n. 1517, p. 2.

O MATTO GROSSO. Theatro no Lyceu Salesiano. Cuyabá: 2 de março de 1919a, ano XXX, n. 1552, p. 7. 
O MATTO GROSSO. Temporada Theatral. Cuyabá: 29 de maio de 1919b, ano XXX, n. 1575 , p. 2.

O MATTO GROSSO. Temporada Theatral. Cuyabá: 05 de junho de 1919c, ano: XXX, n. 1577, p. 3.

O MATTO GROSSO. Cuyabá: 16 de setembro de 1928a, ano XXXIV, n. 2121, p. 1.

O MATTO GROSSO. Cuyabá: 04 de novembro de 1928b, ano XL, n. 2128, p. 2.

O REPUBLICANO. Aviso. Cuyabá: 27 de fevereiro de 1896a, ano I, n. 31, p. 3.

O REPUBLICANO. Cuyabá: 02 de abril de 1896b, ano I, n. 41, p. 1.

O REPUBLICANO. Cuyabá: 02 de julho de 1896c, ano I, n. 67. p.2

O REPUBLICANO. Choniqueta. Cuyabá: 08 de agosto de 1897, ano II, n. 182, p. 3.

O REPUBLICANO. Cuyabá: 17 de janeiro de 1898a, ano III, n. 237, p. 4.

O REPUBLICANO. O Convite. Cuyabá: 24 de abril de 1898b, ano III, n. 256, p. 4.

O REPUBLICANO. Festas do Divino Espírito Santo. Cuyabá: 01 de maio de 1898c, ano III, n. 258 , p. 4.

O SERTANEJO. Grêmio Familiar Corumbaense. Corumbá: 9 de dezembro de 1897, ano I, n. 14, p. 3.

PAIVA, S. C. Viva o Rebolado! Vida e Morte do Teatro de Revista Brasileiro. Rio de Janeiro: Nova Fronteira, 1991.

PRADO, Décio de Almeida. História concisa do teatro brasileiro: (1570 a 1908). São Paulo: Edusp, 1999. p.19. Disponível em: <https://www.livrebooks.com.br/livros/ historia- concisa do- teatro- brasileiro- decio- de- almeida- prado-u6m3ccq1bp0c/baixa ebook>, acessado em: 29/05/2017.

RODRIGUES, Eni Neves da Silva. Impressões em preto e branco: História da leitura em Mato Grosso na segunda metade do século XIX. (Tese Doutorado) da Universidade Estadual de Campinas. Campinas: 2008.

SÁ, Jussara Bittencourt de. A nação brasileira em cena. (Tese Doutorado). Centro de Comunicação e Expressão do Programa de Pós-Graduação em Literatura da Universidade Federal de Santa Catarina. Florianópolis, 2005. p. 29.

SANTOS. Natália Gonçalves de Souza. O pensamento crítico de Álvares de Azevedo por meio de seus prefácios: antagonismo e dissolução. (Dissertação Mestrado). Faculdade de Filosofia, Letras e Ciências Humanas da Universidade de São Paulo. São Paulo: 2012.

SILVA, Agnaldo Rodrigues da. O Teatro mato-grossense: história, crítica e textos. Cáceres: Abrali Edições/ Editora UNEMAT, 2010.

SIQUEIRA, Elizabeth Madureira. História de Mato Grosso da ancestralidade aos dias atuais. Cuiabá: Entrelinha, 2002, pp. 152-197.

SCANDAROLLI, Denise. Estruturação do gênero "cômico" no Teatro Francês: Vaudeville e Opéra-Comique. In: Anais do XXI Encontro Estadual de História - ANPUHSP. Campinas: setembro, 2012, p. 2. Disponível em: <http://www.encontro2012.sp.anpuh.org/resources/anais/17/1342532421_ARQUIVO_

OsgeneroscomicosdaOperaFrancesa.pdf $>$, acessado em 05/01/2017.

TRIBUNA. Theatro N. S. dos Remédios Ladário. Corumbá: 09 de junho de 1928, ano XVII, n. 6284, p. 4.

SOUZA, João Carlos de Souza. Sertão Cosmopolita: tensões da modernidade de Corumbá (1872 - 1918). São Paulo: Alameda, 2008. 